\title{
Iron repletion is associated with reduction in platelet counts in non-dialysis chronic kidney disease patients independent of erythropoiesis- stimulating agent use: a retrospective cohort study
}

\author{
Lenar Yessayan ${ }^{1 *}$, Jerry Yee ${ }^{1}$, Gary Zasuwa ${ }^{1}$, Stan Frinak ${ }^{1}$ and Anatole Besarab²
}

\begin{abstract}
Background: Iron deficiency is common in non-dialysis chronic kidney disease (ND-CKD) patients and, on occasion, requires parenteral iron therapy. We investigated the effect of intravenous iron repletion on platelet counts in ND-CKD patients with and without concomitant darbepoetin administration.

Methods: We conducted a retrospective analysis of ND-CKD patients with iron deficiency anemia treated with low molecular weight iron dextran (LMWID) between 2005 and 2009 at our CKD clinic. The primary end-point was change in platelet count 60 days post infusion of LMWID in those with and without concomitant darbepoetin administration. Secondary end-points were the correlations between changes in platelet count and iron indices.

Results: A total of 108 patients met inclusion and exclusion criteria. The decrease in platelet counts in response to iron repletion was statistically significant (305.72 \pm 108.86 vs $255.58 \pm 78.97, P=<.0001$ ). The decrease in platelet count was independent of concomitant darbepoetin use. Bivariate regression analysis between baseline platelet count and transferrin saturation by iron (TSAT) showed a negative association ( $\beta_{\text {TSAT }}=-5.82, \mathrm{P}=.0007$ ) and moderate correlation $(R=0.32)$. Following iron treatment, the within individual changes in platelet count in 60 days were not related to changes in TSAT ( $\left.\beta_{\triangle T S A T}=-0.41, P=.399\right)$ and demonstrated a poor correlation $(R=0.10)$.

Conclusions: Parenteral iron treatment by LMWID is associated with reduction in platelet counts in iron deficient anemic ND-CKD patients. However, ESA use in the majority of patients prior to intravenous iron administration could have altered platelet production through bone marrow competition.
\end{abstract}

Keywords: Thrombocytosis, Platelet count, Iron deficiency anemia, Erythropoietin, Intravenous iron dextran

\section{Background}

Thrombocytosis may be the result of a clonal disorder or secondary to a reactive process such as acute or chronic inflammation, hyposplenism, malignancy, or iron deficiency. The mechanism of thrombocytosis in iron deficiency related anemia is not completely understood. Thrombocytopoiesis is orchestrated by a complex interplay between growth factors and cytokines. Thrombopoietin is the primary growth factor and regulator of megakaryopoiesis [1]; however, several other cytokines

\footnotetext{
* Correspondence: lyessay1@hfhs.org

'Division of Nephrology and Hypertension, Henry Ford Hospital, 2799 W. Grand Blvd, CFP-514, Detroit, MI, USA

Full list of author information is available at the end of the article
}

such as interleukin (IL)-1, IL-3, IL-6, IL-11 and tumor necrosis factor are involved in this process [2-7]. Erythropoietin shares some structural features with thrombopoietin and may exhibit synergistic effect on platelet production $[8,9]$. However, the small degree of functional overlap is not mediated by cross-reactivity at the level of mpl receptor expressed on the surface of megakaryocytes [10]. Treatment with exogenous erythropoietin may increase platelet count [11]. It may be that the mechanism of synergy is mediated through the expression of erythropoietin receptors on megakaryocyte progenitors. It has also been suggested that the mechanism by which erythropoiesis stimulating agents (ESA) increase platelet count may be through the induction of a state of functional iron 
deficiency [12]. Some have suggested that reactive thrombocytosis, induced by ESA or the resulting iron depletion, may have contributed to the higher-than-expected rates of cerebrovascular accidents and thrombotic events reported in clinical trials of ESA in chronic kidney disease (CKD) patients. At the Henry Ford Hospital Chronic Kidney Disease Clinic, low molecular weight iron dextran (LMWID) in conjunction with ESA is used for non-dialysis chronic kidney disease (ND-CKD) anemia management using a computerized algorithm for dosing. We undertook the present study to evaluate the temporal effect of intravenous iron administration on platelet counts in iron deficient ND-CKD patients and determine if the effect is dependent on concurrent ESA administration.

\section{Methods}

This single-center retrospective cohort study was approved by our hospital's institutional review board (IRB project number 6650; Henry Ford Health Systems Institutional Review Board). We performed a chart review of all ND-CKD patients enrolled in our CKD clinic's computerized anemia management program (CAMP) [13] who received iron dextran (INFeD, Watson Pharmaceuticals, Parsippany, NJ) between August 25, 2005 and March 6, 2009. CAMP is designed to treat anemia of CKD using darbepoetin alpha (DA) and iron treatment algorithms. Data on patients' hematologic variables are stored in the CAMP database irrespective of whether they received the recommended dose of iron/ESAs. After manual data input, the iron dosing algorithm recommends no iron, oral iron, or $1 \mathrm{~g}$ of LMWID over 1.52 hours based on hemoglobin, TSAT, and ferritin levels obtained within 30 days of iron infusion. At all times, iron "sufficiency" is to be achieved/maintained with oral or parenteral ID per the algorithm [14]. The dosing of LMWID (500 or $1000 \mathrm{mg}$ ) during this study period was at the discretion of the treating physician. DA doses were determined monthly, based on three separate protocols for first, second, and maintenance DA doses with the goal to achieve and maintain $\mathrm{Hb}$ in the range of $10.0-12.0 \mathrm{~g} / \mathrm{dL}$ [13].

Eligible patients were adults ( $\geq 18$ years) with CKD who received a single dose of LMWID during a 2-month period and who were not on maintenance ESA therapy prior to LMWID administration. Exclusion criteria were any of the following: documented surgery, gastrointestinal bleeding, hospitalization during the evaluation period; lack of follow-up on second evaluation (within 37 days from baseline) or on third evaluation (within 37 days from second evaluation); administration of ESAs within 30 days of LMWID infusion. Of the 131 subjects identified, 108 ND-CKD patients met eligibility criteria. All of these study subjects received either a $500 \mathrm{mg}$ or $1000 \mathrm{mg}$ infusion by peripheral vein over 1.5-2.0 hours.
No patient received a LMWID test dose and none were premedicated with diphenhydramine. We previously reported that LMWID is safe and effective in the treatment of iron deficiency in ND-CKD [14]. However, because fatal anaphylactic reactions have been reported after administration of LMWID injection, resuscitation techniques and treatment of anaphylactic and anaphylactoid shock are readily available in our CKD clinic.

Baseline platelet counts, hemoglobin and iron indices were obtained within 1 week prior to LMWID administration, at 30 and 60 days post LMWID administration. The primary end-point was the change in platelet count at $\sim 60$ days from iron administration (baseline) in those with and without concomitant DA administration. Secondary end-points were changes in iron indices at $\sim 30$ and 60 days from baseline and the correlation between changes in iron indices and platelet count following LMWID administration. To detect a reduction in platelets of $25000 / \mathrm{mm}^{3}$ with a two-sided $5 \%$ significance level and a power of $80 \%$, a sample size of at least 60 patients was necessary to account for an anticipated $20 \%$ exclusion, either because of lack of follow-up or presence of intercurrent events. To include at least this number of patients, a 48-month inclusion period was considered.

Statistical analysis was performed using SAS software version 9.3 (SAS Institute, Inc., Cary, NC). We used Student's paired $t$-test to measure intra individual changes between time points for platelets, ferritin, and TSAT. Pearson correlation coefficients were used to evaluate the relationship between platelet count and iron indices at baseline as well as between changes in platelet counts and iron indices 60 days post-administration. Categorical variables are presented as frequencies and percentages. Continuous variables are presented using mean \pm standard deviation. For all analyses, a $\mathrm{P}$ value $<.05$ was considered significant.

\section{Results}

Table 1 shows demographics and baseline laboratory values of 108 patients receiving LMWID infusions stratified by concomitant DA use. All CKD stages were represented (Table 1). Stages 3 and 4 CKD were the most common and CKD stage 1 was the least common. There were 65 (60\%) $1000 \mathrm{mg}$ LMWID infusions and 43 (40\%) $500 \mathrm{mg}$ LMWID infusions administered. Of the $108 \mathrm{sub}-$ jects, 94 received monthly DA injections either on the day of iron infusion or 30 days prior to iron infusion or both; and 14 patients did not receive any DA within 30 days prior to iron infusion or during the evaluation period. Figure 1 shows the mean monthly doses of DA over time in the DA group.

Following administration of LMWID, hemoglobin, ferritin, and iron saturation increased significantly at 30 
Table 1 Baseline characteristics of patients receiving intravenous iron dextran stratified by darbepoetin exposure

\begin{tabular}{|c|c|c|c|}
\hline & $\begin{array}{l}\text { Darbepoetin } \\
\qquad N=94\end{array}$ & $\begin{array}{l}\text { No darbepoetin } \\
\qquad N=14\end{array}$ & $P$ value \\
\hline \multicolumn{4}{|l|}{ Demographics } \\
\hline Age & $69.51 \pm 15.90$ & $67.79 \pm 17.26$ & $0.7088(\mathrm{~T})$ \\
\hline Race, $n$ (White, Black, Asian, Hispanic) & $45 / 47 / 1 / 1$ & $13 / 1 / 0 / 0$ & $0.0181(\mathrm{~F})$ \\
\hline Gender, $n$ (Female/Male) & $58 / 36$ & $11 / 3$ & $0.2202(C)$ \\
\hline \multicolumn{4}{|l|}{ Laboratory } \\
\hline Baseline platelets $\left(1000 / \mathrm{mm}^{3}\right)$ & $304.53 \pm 106.97$ & $313.71 \pm 124.87$ & $0.7699(\mathrm{~T})$ \\
\hline Hemoglobin (g/dL) & $9.98 \pm 1.22$ & $11.44 \pm 1.43$ & $<0.0001(\mathrm{~T})$ \\
\hline Transferrin saturation (\%) & $13.07 \pm 6.26$ & $12.71 \pm 4.41$ & $0.8361(\mathrm{~T})$ \\
\hline Ferritin $(\mathrm{ng} / \mathrm{mL})$ & $43.07 \pm 36.05$ & $33.50 \pm 23.10$ & $0.3379(\mathrm{~T})$ \\
\hline \multicolumn{4}{|l|}{ CKD stage } \\
\hline Stage 1 & $1(1 \%)$ & $0(0 \%)$ & $0.4453(C)$ \\
\hline Stage 2 & $6(6 \%)$ & $0(0 \%)$ & \\
\hline Stage 3 & $40(43 \%)$ & $9(64 \%)$ & \\
\hline Stage 4 & $38(40 \%)$ & $5(36 \%)$ & \\
\hline Stage 5 & $9(10 \%)$ & $0(0 \%)$ & \\
\hline
\end{tabular}

Demographics are reported as frequencies except for age which is reported as mean \pm standard deviation. Laboratory parameters are reported as mean \pm standard deviation. Chronic kidney disease $(C K D)$ stages are reported as frequencies with percentages in parenthesis. $(T)=$ Two-sided T-Test, $(C)=C h i-S q u a r e ~ T e s t, ~(F)=$ Fisher Exact Test.

and 60 days. Concomitantly, at 30 and 60 days, a statistically significant decrease occurred in platelet counts in response to iron repletion (Table 2). When platelet response was stratified according to DA use (Table 3), there was a statistically significant decrease in platelet counts from baseline at 30 days in both groups (DA group $304.53 \pm 106.97$ vs $274.26 \pm 136.27, \mathrm{P}=0.008$; No DA group $313.71 \pm 124.87$ vs $279.00 \pm 130.08, \mathrm{P}=0.0021$ ). At 60 days, a statistically significant decrease in platelet counts of approximately $50000 / \mathrm{mm}^{3}$ was observed in both groups in response to iron repletion. The change in platelet count was similar when stratified according to DA

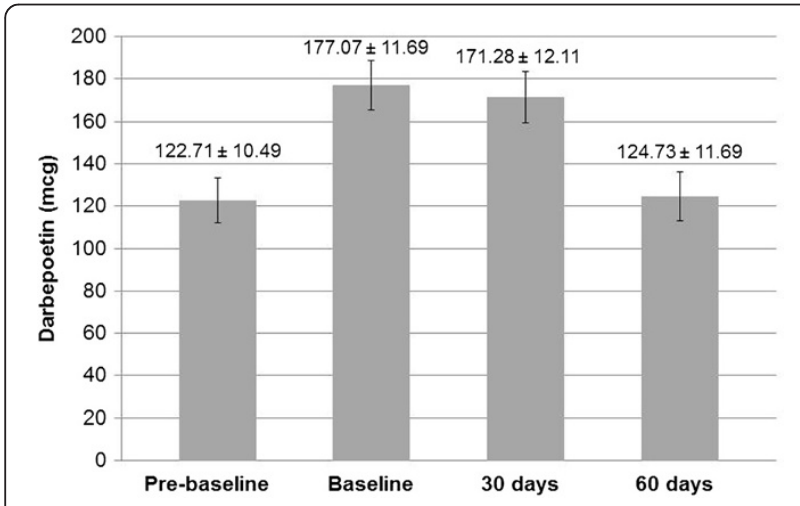

Figure 1 Darbepoetin alfa $(\mathrm{mcg}) \pm$ SD utilization over duration of study in the group that received Darbepoetin alfa. Pre-baseline indicates within 30 days of iron infusion. Baseline indicates the day of iron infusion. use $(-50.12 \pm 63.36$ for DA group vs $-50.29 \pm 74.64$ for No DA group, $\mathrm{P}=.9928)$. Irrespective of iron dose, a decrease in platelet count was observed (Table 4). The change in platelet count 60 days post-LMWID was similar when platelet response was stratified according to dose of LMWID administered $(-50.33 \pm 61.40$ for $500 \mathrm{mg}$ vs $-50.02 \pm 67.02$ for $1000 \mathrm{mg}$; $\mathrm{P}=.9806)$.

Bivariate regression analysis between the baseline platelet count and TSAT revealed a negative association between the 2 variables. The estimated baseline platelet count increased by $\approx 5820$ for each $1 \%$ decrease in TSAT $\left(\beta_{\text {TSAT }}=-5.82, \mathrm{P}=.0007\right)$. The correlation coefficient $R$ between baseline platelet and TSAT was 0.32 . No association was found between baseline platelet count and ferritin $\left(\beta_{\text {ferritin }}=-0.32, \mathrm{P}=.2838\right)$, and the correlation coefficient $R$ was not significant $(R=0.10, \mathrm{P}=.2838)$.

The linear correlation between changes in platelet counts and iron indices in response to LMWID at 60 days was also investigated. The change in platelet count in $\sim 60$ days was neither related to changes in iron saturation $\left(\beta_{\triangle \mathrm{TSAT}}=-0.41, \mathrm{P}=.3991\right)$ nor ferritin $\left(\beta_{\text {ferritin }}=\right.$ $0.07, \mathrm{P}=.1458)$, as displayed in Figures 2 and 3, respectively. Both predictor variables exhibited a weak and statistically non-significant correlation with platelet change ( $R=-0.09, R=-0.15$, respectively). To test the robustness of this result, we repeated this analysis after the exclusion of patients who did not have any improvement in their TSAT by 60 days from baseline. The poor correlation persisted even after the exclusion of these patients $(R=$ $-0.07934)$. 
Table 2 Parameter comparison at baseline, 30 days and 60 days post-LMWID administration

\begin{tabular}{lcccr}
\hline Parameter & $\begin{array}{c}\text { Pre-infusion } \\
\text { Mean } \pm \text { SD }\end{array}$ & $\begin{array}{c}\text { 30 days } \\
\text { Mean } \pm \text { SD }\end{array}$ & p-value & 60 days \\
Mean \pm SD
\end{tabular}

\section{Discussion}

Secondary thrombocytosis is associated with many conditions, including acute or chronic inflammation, hyposplenism, and iron deficiency. Although generally regarded as a benign condition, secondary thrombocytosis has been identified as an independent risk factor for thromboembolic events in patients with cancer [15-17]. Similarly, iron deficiency with and without thrombocytosis has been linked to venous thrombosis and stroke [18-20]. Thus, it is biologically plausible that reactive thrombocytosis, induced by ESA or the resulting iron depletion, may have contributed to the higher-thanexpected rates of cerebrovascular accidents and thrombotic events reported in clinical trials of ESA in CKD patients (e.g., the cardiovascular risk reduction by early anemia treatment with epoetin beta [CREATE] trial, a trial of end-stage renal disease patients that compared the effects of normal as compared with low hematocrit values in patients with cardiac disease who were receiving hemodialysis and epoetin, and a trial to reduce cardiovascular events with Aranesp therapy [TREAT]) [21-23] as postulated by Streja et al. [24]. In their retrospective analysis of more than 40000 hemodialysis patients, Streja et al. [24] noted relative thrombocytosis in $15 \%$ (defined as platelet count $>300000 \pm 109000 / \mathrm{L}$ ), and this was associated with a $30 \%$ greater weekly dose of ESA, lower TSAT, and lower serum ferritin concentration. This pattern is reflective of functional iron deficiency at the bone marrow level.

Megakaryopoiesis is regulated by various cytokines [1-7]. The pathophysiologic mechanism behind reactive thrombocytosis in iron deficiency is complex and incompletely understood. Akan et al. [25] demonstrated that the correction of iron deficiency anemia and resolution of thrombocytosis do not alter cytokine levels that are typically elevated in reactive thrombocytosis (IL-6, IL-11, and thrombopoietin). Although the levels of endogenous erythropoietin significantly decreased during correction of iron deficiency, the same response was observed in those with and without thrombocytosis, indicating that erythropoietin is not the principal regulator of thrombocytosis [25].

Studies of intravenous iron undertaken in predialysis chronic renal failure that evaluated hematologic parameters have not reported the effect on platelet counts [26-30]. This observational study evaluated the effect of intravenous LMWID on platelet counts in iron deficient anemic ND-CKD patients with and without concomitant ESA use. We also evaluated the relationship between baseline platelets and iron storage parameters, as well as the relationship between changes in iron storage parameters and platelets. In response to iron administration, a

Table 3 Parameter comparison pre-LMWID and post-LMWID infusion stratified by darbepoetin administration

\begin{tabular}{|c|c|c|c|c|c|}
\hline \multicolumn{6}{|c|}{ Darbepoetin $(\mathrm{N}=94)$} \\
\hline \multirow[t]{2}{*}{ Parameter } & Pre-infusion & 30 days & p-value & 60 days & p-value \\
\hline & Mean \pm SD & Mean \pm SD & \multicolumn{3}{|c|}{ Mean \pm SD } \\
\hline Platelet count $\left(1000 / \mathrm{mm}^{3}\right)$ & $304.53 \pm 106.97$ & $274.26 \pm 136.27$ & 0.008 & $254.41 \pm 80.16$ & $<0.0001$ \\
\hline Hemoglobin (g/dL) & $9.98 \pm 1.22$ & $11.12 \pm 1.61$ & $<0.0001$ & $11.22 \pm 1.70$ & $<0.0001$ \\
\hline Ferritin $(\mathrm{ng} / \mathrm{mL})$ & $43.07 \pm 36.05$ & $208.06 \pm 171.79$ & $<0.0001$ & $150.58 \pm 151.79$ & $<0.0001$ \\
\hline Transferrin saturation (\%) & $13.07 \pm 6.26$ & $24.32 \pm 12.83$ & $<0.0001$ & $25.83 \pm 13.55$ & $<0.0001$ \\
\hline \multicolumn{6}{|c|}{ No Darbepoetin $(\mathrm{N}=14)$} \\
\hline \multirow[t]{2}{*}{ Parameter } & Pre-infusion & 30 days & p-value & 60 days & $\mathrm{p}$-value \\
\hline & Mean \pm SD & Mean \pm SD & \multicolumn{3}{|c|}{ Mean \pm SD } \\
\hline Platelet count $\left(1000 / \mathrm{mm}^{3}\right)$ & $313.71 \pm 124.87$ & $279.00 \pm 130.08$ & 0.0021 & $263.43 \pm 72.68$ & 0.0256 \\
\hline Hemoglobin (g/dL) & $11.44 \pm 1.43$ & $12.66 \pm 1.51$ & 0.0049 & $12.46 \pm 1.30$ & 0.0053 \\
\hline Ferritin $(\mathrm{ng} / \mathrm{mL})$ & $33.50 \pm 23.10$ & $135.00 \pm 103.01$ & 0.0276 & $192.25 \pm 208.21$ & 0.0620 \\
\hline Transferrin saturation (\%) & $12.71 \pm 4.41$ & $16.00 \pm 6.07$ & 0.1047 & $16.75 \pm 5.92$ & 0.0683 \\
\hline
\end{tabular}

LMWID = low molecular weight iron dextran. 
Table 4 Parameter comparison pre-LMWID and 60 days post-LMWID infusion stratified by iron dextran dose

\begin{tabular}{|c|c|c|c|c|c|c|}
\hline & \multicolumn{3}{|c|}{$\begin{array}{l}\text { Iron dextran } 1000 \mathrm{mg} \\
\qquad \mathrm{N}=65\end{array}$} & \multicolumn{3}{|c|}{$\begin{array}{l}\text { Iron dextran } 500 \mathrm{mg} \\
\qquad \mathrm{N}=43\end{array}$} \\
\hline & $\begin{array}{c}\text { Pre-infusion } \\
\text { Mean } \pm \text { SD }\end{array}$ & $\begin{array}{c}\text { Post-infusion } \\
\text { Mean } \pm \text { SD }\end{array}$ & $P$ value & $\begin{array}{c}\text { Pre-infusion } \\
\text { Mean } \pm \text { SD }\end{array}$ & $\begin{array}{l}\text { Post-infusion } \\
\text { Mean } \pm \text { SD }\end{array}$ & $P$ value \\
\hline Platelet count $\left(1000 / \mathrm{mm}^{3}\right)$ & $323.54 \pm 118.82$ & $273.52 \pm 87.34$ & $<0.0001$ & $278.79 \pm 86.27$ & $228.47 \pm 54.87$ & $<0.0001$ \\
\hline Hemoglobin (g/dL) & $10.24 \pm 1.41$ & $11.60 \pm 1.63$ & $<0.0001$ & $10.07 \pm 1.23$ & $11.04 \pm 1.78$ & 0.0001 \\
\hline Ferritin $(\mathrm{ng} / \mathrm{mL})$ & $46.22 \pm 38.31$ & $174.60 \pm 158.25$ & $<0.0001$ & $35.21 \pm 27.54$ & $122.59 \pm 150.15$ & 0.0005 \\
\hline Transferrin saturation (\%) & $13.60 \pm 6.43$ & $24.95 \pm 12.12$ & $<0.0001$ & $12.16 \pm 5.34$ & $25.24 \pm 15.07$ & $<0.0001$ \\
\hline
\end{tabular}

LMWID = low molecular weight iron dextran.

statistically significant decrease occurred in platelet counts of about $50000 / \mathrm{mm}^{3}$, suggesting a mechanistic link between iron deficiency and platelet counts in patients with ND-CKD. The effect of iron repletion on platelet count was observed in those who did and did not receive ESAs suggesting that the effect of iron repletion on platelet counts is independent of ESA use.

In our study the correlation between baseline platelet and TSAT was weak to moderate and negative in direction $(R=-0.31)$; this is consistent with previously reported negative associations between baseline iron stores and platelet counts. One recent study showed only a very weak correlation between baseline platelet count and iron stores and no reduction in platelet count after intravenous iron dextran [31]. However, contrary to our study, the after dose values were measured between 10120 days. Interestingly, when we investigated the relationship of within individual change in platelet count in response to a change in TSAT, we only found a weak and insignificant correlation. This would imply that our current parameters for iron deficiency, TSAT and ferritin,

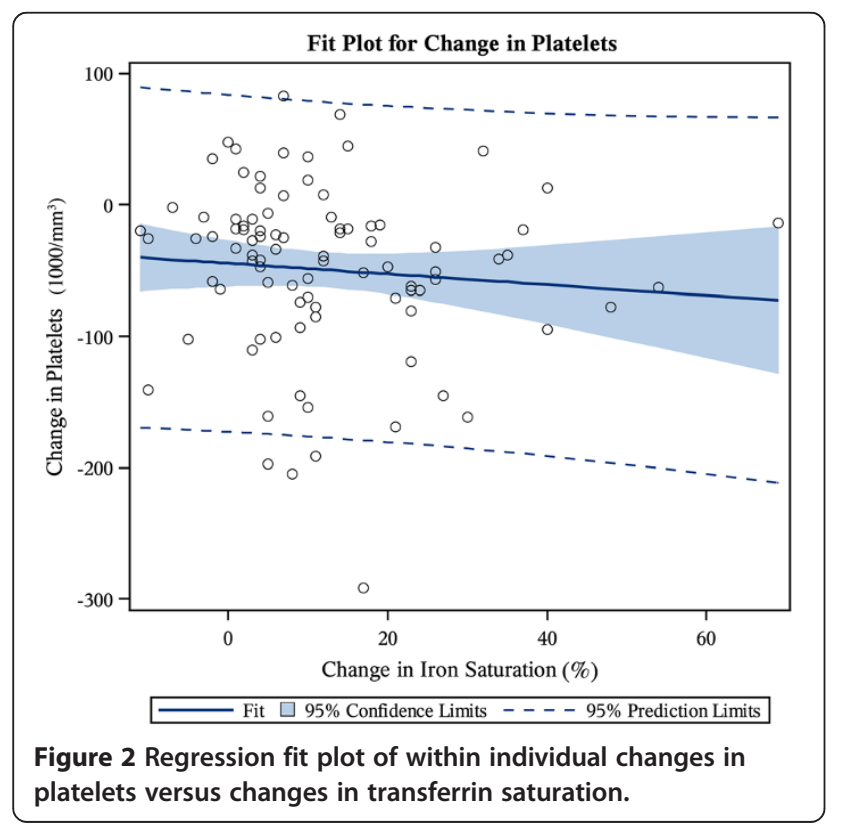

may be insensitive and imprecise measures of iron availability to the bone marrow. To date, the only definitive way in clinical practice to prove the presence of iron deficiency in CKD is to evaluate the erythropoietic response to parenteral iron administration. However, both reticulocyte hemoglobin content $(\mathrm{CHr})$ and the percentage of hypochromic red cells may be better indicators of iron deficiency $(\mathrm{CHr}$ area under the curve $[\mathrm{AUC}]=0.935$ for a cutoff of $29.8 \mathrm{pg}$, sensitivity $90.7 \%$, specificity $83.1 \%$; percent hypochromic cells AUC $=0.925$, cutoff $3.5 \%$, sensitivity $87.3 \%$, and specificity $88.0 \%$ ) [32] than the traditional measurements of TSAT and ferritin, which have sensitivities and specificities $<80 \%$.

This study has several limitations. Its retrospective nature makes it subject to selection and information bias. Selection bias was constrained by including all patients within the prespecified dates; however, some patients were excluded because of a lack of follow-up or intercurrent events. Moreover, given the retrospective design, patients with undocumented intercurrent events in our records such as gastrointestinal bleed, infection and

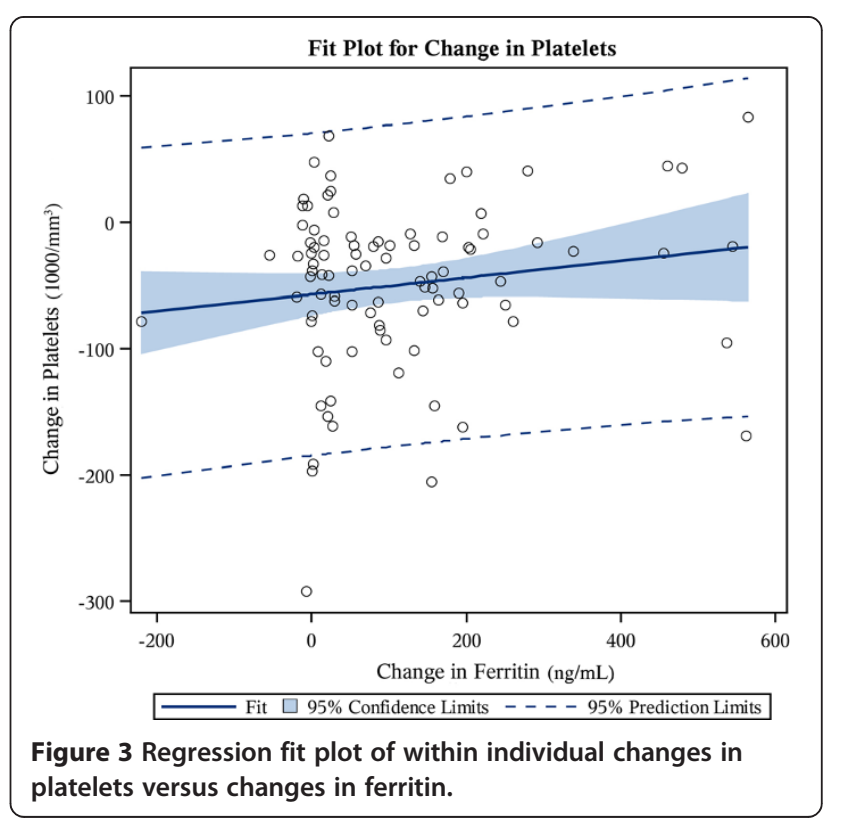


surgery may have been included in the study and caused bias in the point estimate of the correlation. However, an uncertainty analysis that was performed with the exclusion of those who did not have any improvement in their TSAT yielded similar results. Additionally, by design, we could not fully control information bias; however, any observer bias was limited by data abstraction from the anemia management database. This study suggests that iron replacement is associated with reduction in platelet counts in iron deficient ND-CKD patients independent of ESA use and extends the observation of Eschbach's study [33], where it was noted that almost half of their 333 study patients developed iron deficiency with platelet counts increasing following erythropoietin administration to anemic end-stage renal disease patients. Aggressive iron therapy reversed this increase in platelets.

Another limitation was the absence of data regarding inflammatory markers, such as C-reactive protein and erythrocyte sedimentation rate, and for this reason, we could not adjust for the effect of inflammatory status, if any, on platelet count change. Furthermore, the majority of our patients did not have thrombocytosis $($ median $=$ 284000 , interquartile range $=236-359$ ). The decrease in platelet count following LMWID could only be extrapolated to patients within the specified platelet count range in our cohort. Whether iron administration could induce a more pronounced change in platelet count in iron deficient patients with thrombocytosis warrants further investigation.

\section{Conclusion}

In conclusion, our study implies that intravenous iron is associated with reduction in platelet counts independent of ESA use. However, without a control group not receiving IV iron, causation cannot be confirmed. Adequately powered studies are needed to establish an association between thrombocytosis, iron deficiency and thromboembolic events in ND CKD patients.

\footnotetext{
Abbreviations

AUC: Area under the curve; CAMP: Computerized anemia management program; CHr: Reticulocyte hemoglobin content; DA: Darbepoetin; ESA: Erythropoietin stimulating agent; IL: Interleukin; LMWID: Low molecular weight iron dextran; ND-CKD: Non-dialysis chronic kidney disease; TSAT: Transferrin saturation.

\section{Competing interests}

L. Yessayan has nothing to disclose. J. Yee, A. Besarab, S. Frinak and G. Zasuwa are inventors of Computerized Algorithm Management Program (CAMP). A. Besarab has received research funds, grants, or contracts from Affymax, Amgen Inc., Hoffman-La Roche Ltd., Rockwell International, Takeda Pharmaceuticals, VascAlert, Fibrogen Inc., Watson Pharmaceuticals, and Bayer Pharma. J. Yee is a consultant for Amgen, Affymax, Merck, and Alexions and a shareholder in Merck.
}

\section{Authors' contributions}

$A B$ is the principal investigator and conceived the study. $L Y, J Y, G Z$ and $S F$ contributed to study design. JY, GZ and SF acquired the data. $L Y, J Y$ and $A B$ analyzed and interpreted the data. LY, JY and AB wrote the manuscript. LY, $J Y$, and $A B$ revised the manuscript for important intellectual content. All authors read and approved the final manuscript.

\section{Acknowledgements}

The authors express their gratitude to Sarah Whitehouse, MAW, Department of Internal Medicine, Henry Ford Hospital, for her expert editorial assistance. They also extend their gratitude to Stephanie Stebens, MLIS, Sladen Library, Henry Ford Hospital, for assistance with manuscript preparation.

\section{Author details}

1Division of Nephrology and Hypertension, Henry Ford Hospital, 2799 W. Grand Blvd, CFP-514, Detroit, MI, USA. ²Division of Nephrology and Hypertension, University of California, San Francisco, CA, USA.

Received: 10 March 2014 Accepted: 16 July 2014

Published: 19 July 2014

\section{References}

1. Kaushansky K: Thrombopoietin: the primary regulator of platelet production. Blood 1995, 86(2):419-431.

2. Haznedaroglu IC, Ertenli I, Ozcebe OI, Kiraz S, Ozdemir O, Sayinalp NM, Dundar SV, Calguneri M, Kirazli S: Megakaryocyte-related interleukins in reactive thrombocytosis versus autonomous thrombocythemia. Acta Haematol 1996, 95(2):107-111.

3. Wendling F, Han ZC: Positive and negative regulation of megakaryocytopoiesis. Baillieres Clin Haematol 1997, 10(1):29-45.

4. Hsu HC, Tsai WH, Jiang ML, Ho CH, Hsu ML, Ho CK, Wang SY: Circulating levels of thrombopoietic and inflammatory cytokines in patients with clonal and reactive thrombocytosis. J Lab Clin Med 1999, 134(4):392-397.

5. Hamaguchi H, Takano N, Saito K, Enokihara H, Furusawa S, Shishido H: Interaction of monocytes and T cells in the regulation of normal human megakaryocytopoiesis in vitro: role of IL-1 and IL-2. Br J Haematol 1990, 76(1):12-20.

6. Alexandrakis MG, Passam FH, Moschandrea IA, Christophoridou AV, Pappa CA, Coulocheri SA, Kyriakou DS: Levels of serum cytokines and acute phase proteins in patients with essential and cancer-related thrombocytosis. Am J Clin Oncol 2003, 26(2):135-140.

7. Dan K, Gomi S, Inokuchi K, Ogata K, Yamada T, Ohki I, Hasegawa S, Nomura T: Effects of interleukin-1 and tumor necrosis factor on megakaryocytopoiesis: mechanism of reactive thrombocytosis. Acta Haematol 1995, 93(2-4):67-72.

8. Broudy VC, Lin NL, Kaushansky K: Thrombopoietin (c-mpl ligand) acts synergistically with erythropoietin, stem cell factor, and interleukin-11 to enhance murine megakaryocyte colony growth and increases megakaryocyte ploidy in vitro. Blood 1995, 85(7):1719-1726.

9. Metcalf D, Di Rago L, Mifsud S: Synergistic and inhibitory interactions in the in vitro control of murine megakaryocyte colony formation. Stem Cells 2002, 20(6):552-560.

10. Broudy VC, Lin NL, Sabath DF, Papayannopoulou T, Kaushansky K: Human platelets display high-affinity receptors for thrombopoietin. Blood 1997, 89(6):1896-1904.

11. Beguin $Y$, Loo M, R'Zik S, Sautois B, Lejeune F, Rorive G, Fillet G: Effect of recombinant human erythropoietin on platelets in patients with anemia of renal failure: correlation of platelet count with erythropoietic activity and iron parameters. Eur J Haematol 1994, 53(5):265-270.

12. Beguin Y: Erythropoietin and platelet production. Haematologica 1999, 84(6):541-547.

13. Chalhoub E, Frinak S, Zasuwa G, Faber MD, Peterson E, Besarab A, Yee J: De novo once-monthly darbepoetin alpha treatment for the anemia of chronic kidney disease using a computerized algorithmic approach. Clin Nephrol 2011, 76(1):1-8.

14. Yessayan L, Sandhu A, Besarab A, Yessayan A, Frinak S, Zasuwa G, Yee J: Intravenous iron dextran as a component of anemia management in chronic kidney disease: a report of safety and efficacy. Int J Nephrol 2013, 2013:703038.

15. Khorana AA, Francis CW, Culakova E, Lyman GH: Risk factors for chemotherapy-associated venous thromboembolism in a prospective observational study. Cancer 2005, 104(12):2822-2829.

16. Simanek R, Vormittag R, Ay C, Alguel G, Dunkler D, Schwarzinger I, Steger G, Jaeger U, Zielinski C, Pabinger I: High platelet count associated with venous thromboembolism in cancer patients: results from the Vienna Cancer and Thrombosis Study (CATS). J Thromb Haemost 2010, 8(1):114-120.

17. Zakai NA, Wright J, Cushman M: Risk factors for venous thrombosis in medical inpatients: validation of a thrombosis risk score. $J$ Thromb Haemost 2004, 2(12):2156-2161. 
18. Nagai T, Komatsu N, Sakata Y, Miura Y, Ozawa K: Iron deficiency anemia with marked thrombocytosis complicated by central retinal vein occlusion. Intern Med 2005, 44(10):1090-1092.

19. Kinoshita Y, Taniura S, Shishido H, Nojima T, Kamitani H, Watanebe T: Cerebral venous sinus thrombosis associated with iron deficiency: two case reports. Neurol Med Chir (Tokyo) 2006, 46(12):589-593.

20. Stolz E, Valdueza JM, Grebe M, Schlachetzki F, Schmitt E, Madlener K, Rahimi A, Kempkes-Matthes B, Blaes F, Gerriets T, Kaps M: Anemia as a risk factor for cerebral venous thrombosis? An old hypothesis revisited. Results of a prospective study. J Neurol 2007, 254(6):729-734.

21. Singh AK, Szczech L, Tang KL, Barnhart H, Sapp S, Wolfson M, Reddan D: Correction of anemia with epoetin alfa in chronic kidney disease. $N$ Engl J Med 2006, 355(20):2085-2098.

22. Besarab A, Bolton WK, Browne JK, Egrie JC, Nissenson AR, Okamoto DM, Schwab SJ, Goodkin DA: The effects of normal as compared with low hematocrit values in patients with cardiac disease who are receiving hemodialysis and epoetin. N Engl J Med 1998, 339(9):584-590.

23. Pfeffer MA, Burdmann EA, Chen CY, Cooper ME, de Zeeuw D, Eckardt KU, Feyzi JM, Ivanovich P, Kewalramani R, Levey AS, Lewis EF, McGill JB, McMurray JJ, Parfrey P, Parving HH, Remuzzi G, Singh AK, Solomon SD, Toto $\mathrm{R}$ : A trial of darbepoetin alfa in type 2 diabetes and chronic kidney disease. N Engl J Med 2009, 361(21):2019-2032.

24. Streja E, Kovesdy CP, Greenland S, Kopple JD, MCAllister CJ, Nissenson AR, Kalantar-Zadeh K: Erythropoietin, iron depletion, and relative thrombocytosis: a possible explanation for hemoglobin-survival paradox in hemodialysis. Am $J$ Kidney Dis 2008, 52(4):727-736.

25. Akan H, Guven N, Aydogdu I, Arat M, Beksac M, Dalva K: Thrombopoietic cytokines in patients with iron deficiency anemia with or without thrombocytosis. Acta Haematol 2000, 103(3):152-156.

26. Aggarwal HK, Nand N, Singh S, Singh M, Hemant, Kaushik G: Comparison of oral versus intravenous iron therapy in predialysis patients of chronic renal failure receiving recombinant human erythropoietin. $J$ Assoc Phys o India 2003, 51:170-174.

27. Charytan C, Qunibi W, Bailie GR: Comparison of intravenous iron sucrose to oral iron in the treatment of anemic patients with chronic kidney disease not on dialysis. Nephron Clin Pract 2005, 100(3):c55-62.

28. Spinowitz BS, Kausz AT, Baptista J, Noble SD, Sothinathan R, Bernardo MV, Brenner L, Pereira BJ: Ferumoxytol for treating iron deficiency anemia in CKD. J Am Soc Nephrol 2008, 19(8):1599-1605.

29. Stoves J, Inglis H, Newstead CG: A randomized study of oral vs intravenous iron supplementation in patients with progressive renal insufficiency treated with erythropoietin. Nephrol Dial Transplant 2001, 16(5):967-974.

30. Van Wyck DB, Roppolo M, Martinez CO, Mazey RM, McMurray S: A randomized, controlled trial comparing IV iron sucrose to oral iron in anemic patients with nondialysis-dependent CKD. Kidney Int 2005, 68(6):2846-2856.

31. Dossabhoy NR, Gascoyne R, Turley S: Intravenous iron repletion does Not significantly decrease platelet counts in CKD patients with iron deficiency anemia. Int J Nephrol 2013, 2013:878041.

32. Urrechaga E, Borque L, Escanero JF: Erythrocyte and reticulocyte indices in the assessment of erythropoiesis activity and iron availability. Int J Lab Hematol 2013, 35(2):144-149.

33. Eschbach JW, Abdulhadi MH, Browne JK, Delano BG, Downing MR, Egrie JC, Evans RW, Friedman EA, Graber SE, Haley NR, Korbet S, Krantz SB, Lundin AP, Nissenson AR, Ogden DA, Paganini EP, Rader B, Rutsky EA, Stivelman J, Stone WJ, Teschan P, Van Stone JC, Van Wyck DB, Zuckerman K, Adamson JW: Recombinant human erythropoietin in anemic patients with endstage renal disease. Results of a phase III multicenter clinical trial. Ann Intern Med 1989, 111(12):992-1000.

doi:10.1186/1471-2369-15-119

Cite this article as: Yessayan et al:: Iron repletion is associated with reduction in platelet counts in non-dialysis chronic kidney disease patients independent of erythropoiesis-stimulating agent use: a retrospective cohort study. BMC Nephrology 2014 15:119.

\section{Submit your next manuscript to BioMed Central and take full advantage of:}

- Convenient online submission

- Thorough peer review

- No space constraints or color figure charges

- Immediate publication on acceptance

- Inclusion in PubMed, CAS, Scopus and Google Scholar

- Research which is freely available for redistribution

Submit your manuscript at www.biomedcentral.com/submit 